\title{
Building Up of Frost Depending Upon Conditions of Air Cooler Operation
}

\author{
Abdullah H. M. AlEssa ${ }^{1,2, *}$, Bassam Al-Zgoul ${ }^{2}$ \\ ${ }^{1}$ Department of Mechanical Engineering, Engineering Faculty, Northern Borders University- Arar, Kingdom of Saudi Arabia \\ ${ }^{2} \mathrm{Al}$ - Balqa' Applied University, Al-Huson University College, Al-Huson- Irbid, Jordan
}

\begin{abstract}
In this study the Ivanova's model is modified for different values of relative humidity of the moist air in coolers. The modified model is used to analyze the process of frost accumulation on the surface of finned evaporator coils according to different values of relative humidity and mass velocity of cooled air. The thickness and mass of frost are calculated and illustrated as a function of operation time, relative humidity and mass velocity of cooling air. The results showed that the increase in mass velocity of air from 2 to $8 \mathrm{~kg} / \mathrm{h} . \mathrm{m}^{2}$ caused an increase in frost thickness of 15,13 and $10 \%$ at air with a relative humidity of $0.70,0.80$ and 0.88 , respectively. Frost thickness is obtained after an operation time of 18 hours. In addition to that, it was found that increasing the relative humidity of air from 0.7 to 0.88 caused an increase in frost thickness of $50 \%$ at mass velocity of $4 \mathrm{~kg} / \mathrm{h} \mathrm{m}^{2}$ for the same operation time of $18 \mathrm{hr}$. It means that the increase in relative humidity from 0.70 to 0.88 and mass velocity of air from 2 to $8 \mathrm{~kg} / \mathrm{h} \cdot \mathrm{m}^{2}$ lead to an increase in frost thickness of $65 \%$ for an operation time of $18 \mathrm{hr}$.
\end{abstract}

Keywords Refrigeration, Frost Formation, Moist Air, Relative Humidity, Evaporator, Air Cooler

\section{Introduction}

When humid air contacts cold surfaces of heat exchanger used in refrigerators or air-conditioners, there might happed frosting on the surfaces, if the surface temperature is below the freezing temperature of water. Then the thermal performance of the heat exchanger becomes lower due to the thermal resistance of the frost layer as well as the decrease in airflow area[1]. The growth of frost is a complicated transient process in which both heat and mass transfer occur simultaneously.

Hayashi et al.[2] identified three different periods in frost formation process: (a) a crystal growth period, characterized by a one-dimensional growth of frost crystals in the direction perpendicular to the frosting surface, (b) a frost layer growth period, when the frost crystals interact with other crystals resulting in a uniform frost layer, (c) a frost layer full growth period, when the frost surface reaches $0^{\circ} \mathrm{C}$ and a cyclical process of melting, freezing and deposition occurs until frost formation stops. The time for each period and the shape of the frost crystals were found strongly depend on the cooling surface temperature and the vapor concentration difference between the mean stream and the cooling surface[3].

As the moist air comes in contacts with the evaporators which are below the freezing temperature, the moisture will

* Corresponding author:

abdd104@yahoo.com (Abdullah H. M. AlEssa)

Published online at http://journal.sapub.org/mechanics

Copyright (C) 2012 Scientific \& Academic Publishing. All Rights Reserved condense and form ice (frost) on them and their extended surfaces. So evaporators build up frost continuously when in use. The frost that accumulates on the evaporator and its fins interfere drastically with heat transfer and pressure drop and may eventually block air circulation around the evaporator. It is very important, therefore, that the evaporator surfaces must be defrosted from time to time. The defrosting may be manually or automatically. In the automatic defrosting method, the hot gas cycle or the electric heater cycle are used. In these cycles, the defrosting is operated or energized periodically by using a suitable defrosting timer. The low temperature forced circulation evaporators with small fin spacing need special defrosting care. In food freezing or storage, the effect of frost accumulation on heat transfer surface efficiency must be considered and sufficient defrost time allocated[4, 5].

Evaporators for cold storage applications will be at temperatures lower than $0^{\circ} \mathrm{C}$. Therefore, moisture from the air will freeze on the coil surface. At lower evaporator temperatures, problems of frost formation are greater. Where finned coils are used, frost formation between the fins will obstruct the air passages and affect the quantity of air over the coil. This again will reduce the evaporator temperature, leading to thicker frost formation. The frost in the evaporator coil also acts as insulation and retards heat-transfer. With decreased heat transfer, the evaporator temperature drops, causing a further decrease in efficiency. If allowed to accumulate further, even liquid flood back to the compressor can occur due to reduced evaporator capacity. Frost formation between the fins exerts pressure that can loosen the bond 
of the fin on the evaporator tube. If this happens, the evaporator capacity will diminish, making it is necessary to change the coil. For maximum efficiency from the evaporator, frost formation on evaporator coils should be calculated at operation conditions in advance. This will help the designer make the right decisions for fin spacing, operating temperature of the coil, defrosting frequency, required defrosting time and the capacity of the defrosting system. An attempt to study the process of frost formation was developed by Ivanova[6]. As a result, Ivanova's[7] model was used as an exponential correlation to calculate the thickness of frost at operation conditions of finned evaporator coil. Ivanova's model includes four coefficients that consider the effect of relative humidity on the frost formation as shown in table 3 of Ivanova[7]. In this study, Ivanova's model has been modified to correlations that calculate the thickness and mass of frost directly without data. This will be helpful to create a computer program for a more detailed study of frost formation.

\section{Proposed Models}

Based on experimental study, Ivanova[6] gave the following model to calculate the thickness and mass of frost accumulated on the finned evaporator coil. Thickness of the frost is expressed in exponential correlation as follows:

$$
\delta_{\mathrm{f}}=C_{k}\left(1-e^{-\tau / C_{T}}\right)
$$

These coefficients $\mathrm{C}_{\mathrm{k}}$ and $\mathrm{C}_{\mathrm{T}}$ are given in the following formulas[6]:

$$
\begin{gathered}
\mathrm{C}_{k}=\mathrm{C}_{\mathrm{k}}^{1}+0.051 \mathrm{w} \\
C_{k}=C_{k}^{1}+0.1637 w_{\rho}
\end{gathered}
$$

Frost mass accumulated on unit area of the finned evaporator surface is given in the form of:

$$
\mathrm{g}_{\mathrm{f}}=\mathrm{C}_{\mathrm{g}} \cdot \tau
$$

The coefficient $\mathrm{C}_{\mathrm{g}}$ can be expressed as follows:

$$
\mathrm{C}_{\mathrm{g}}=\mathrm{C}_{\mathrm{g} 1}+\mathrm{C}_{\mathrm{g} 2}\left(w_{\rho}\right)
$$

$\mathrm{C}_{\mathrm{g} 1}$ and $\mathrm{C}_{\mathrm{g} 2}$ are constants which can obtained from[6] in accordance to the relative humidity of moist air passed through the finned evaporator coil $\left(\phi_{a}\right)$. In the present study Ivanova's model is modified for different relative humidity with different coefficients $\left(\mathrm{C}_{\mathrm{k}}, \mathrm{C}_{\mathrm{T}}, \mathrm{C}_{\mathrm{k}}^{1}, \mathrm{C}_{\mathrm{T}}^{1}, \mathrm{Cg}\right)$ and different air mass velocity $\left(w_{\rho} \rho\right)$. The relations obtained are in the form of:

$$
C_{\mathrm{k}}=12.97-32.69 \phi_{a}+24.18 \phi_{a}^{2}+0.0475 w_{\rho}
$$

Thus, thickness of frost could be expressed as follows:

$$
\delta_{\mathrm{f}}=\left(12.97-32.69 \phi_{a}+24.18 \phi_{a}{ }^{2}+0.0475 w_{\rho}\right)\left(1-e^{-\tau / C_{T}}\right)(7)
$$

The coefficient $\mathrm{C}_{\mathrm{T}}$ can be computed by using the following correlation

$$
C_{\mathrm{T}}=-18.35+64.99 \phi_{a}-45.83 \phi_{a}^{2}-0.163 w_{\rho}
$$

The value of $\mathrm{Cg}$ which expresses the effect of relative humidity and mass velocity of air on the intensity of frost mass accumulation can be determined by equation (5).

Where: $\mathrm{C}_{\mathrm{g} 1}$ and $\mathrm{C}_{\mathrm{g} 2}$ are coefficients given by the following equations:

$$
C_{\mathrm{g} 1}=.0052028-.036785 \phi_{a}+.053571 \phi_{a}^{2}
$$

Where $\phi_{a}=(0.70$ to 0.78$)$

$$
\begin{gathered}
C_{\mathrm{g} 1}=-1158.6256+5573.4511 \phi_{a} \\
-10053.396 \phi_{a}{ }^{2}+8058.4738 \phi_{a}{ }^{3}-2421.6068 \phi_{a}{ }^{4} \\
\text { Where } \phi_{a}=(0.80-0.88) \\
C_{\mathrm{g} 2}=-51.7801+339.786 \phi_{a}-890.77966 \phi_{a}{ }^{2} \\
+1166.1847 \phi_{a}{ }^{3}-762.46066 \phi_{a}{ }^{4}+199.19479 \phi_{a}{ }^{5}
\end{gathered}
$$

Where $\phi_{a}=(0.70-0.88)$

Once $\left(g_{f}\right)$ is found, then the total frost mass $(\mathrm{kg})$ accumulated on the finned evaporator coil is determined according to the following equation:

$$
G_{f}=g_{f} \cdot A_{e}
$$

To calculate the average speed of frost accumulation $(\mathrm{mm} /$ hour$)$ the following equation is applied:

$$
V_{f}=\delta_{f} / \tau
$$

\section{Results and Discussion}

The frost accumulation on the finned evaporator coil is calculated by the Ivanova's modified model for the following values

1. Operation of time up to $18 \mathrm{hrs}$ (maximum operation time of refrigeration cycle).

2. Relative humidity of air between 0.70 to 0.88 .

3. Mass velocity of air between 2 to $10 \mathrm{~kg} / \mathrm{h} \mathrm{m}^{2}$.

4. Temperature of air in storage room nearly $0^{\circ} \mathrm{C}$.

5. Temperature difference of 7 to $8^{\circ} \mathrm{C}$.

6 . The evaporator fin spacing is 5 to $15 \mathrm{~mm}$.

Based on the modified model, a computer program has been developed to compute the thickness and mass of frost at different conditions of relative humidity and mass velocity of air. Speed of frost formation $[\mathrm{mm} / \mathrm{hr}]$ is determined according to relative humidity and mass velocity of air as shown in figures 1,2 and 3. These figures show that the effect of mass velocity of air on the frost thickness is not the same at different values of relative humidity. The increasing in mass velocity of air from 2 to $8 \mathrm{~kg} / \mathrm{hr} \cdot \mathrm{m}^{2}$ will cause a frost thickness of 15,13 and $10 \%$ at air relative humidity of 0.70 , 0.80 and 0.88 respectively. 


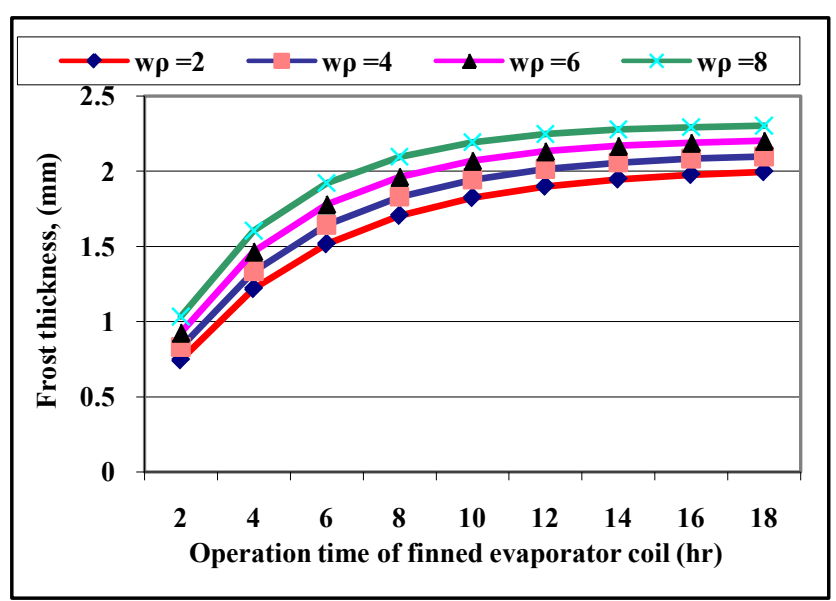

Figure 1. Effect of air mass velocity on the frost thickness at air relative humidity of $70 \%$

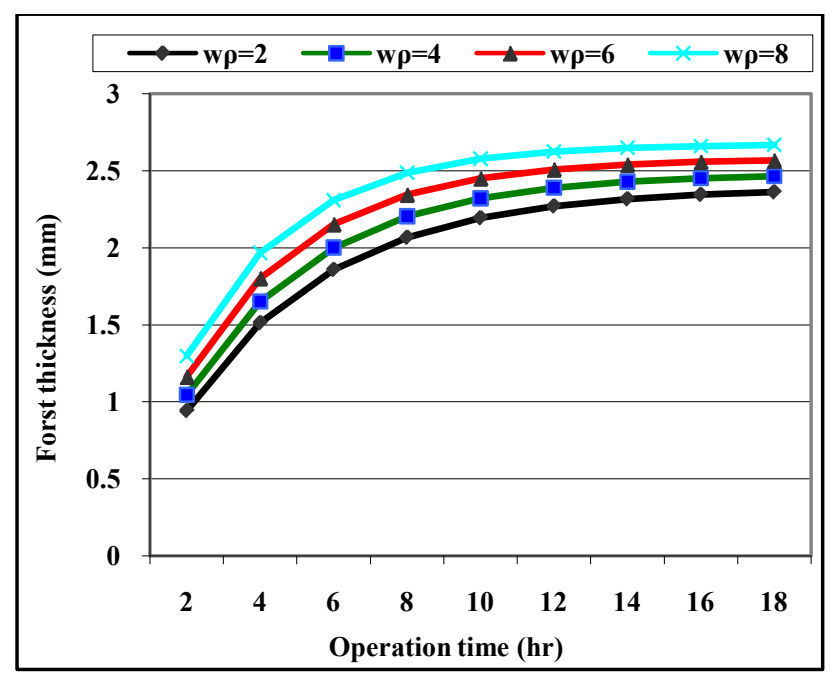

Figure 2. Effect of air mass velocity on the frost thickness at air relative humidity of $80 \%$

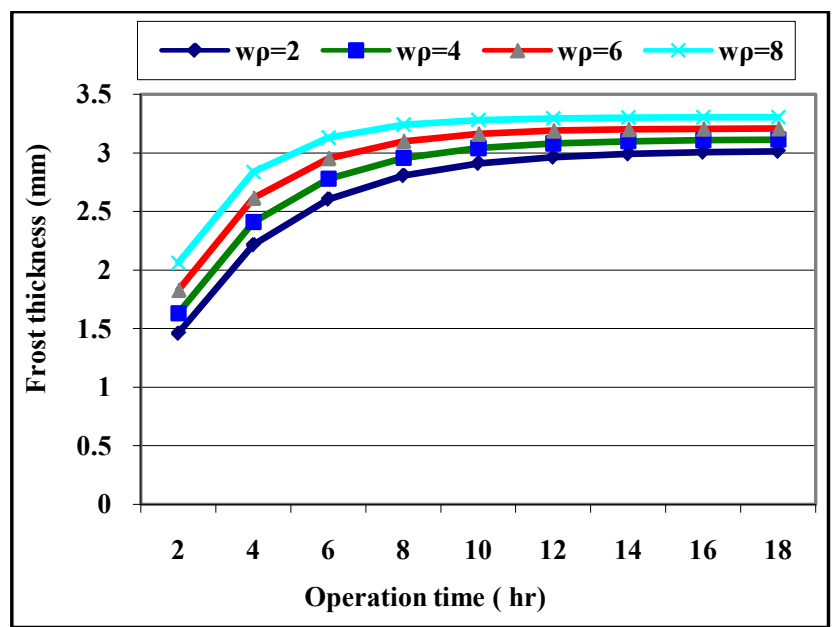

Figure 3. Effect of air mass velocity on the frost thickness at air relative humidity of $88 \%$

The increase in frost thickness is recorded at an operation time of $18 \mathrm{hrs}$. In addition to that, it was found that increase in the relative humidity of air from 0.7 to 0.88 will cause an increase in frost thickness of $50 \%$ at mass velocity of 4 $\mathrm{kg} / \mathrm{hr} . \mathrm{m}^{2}$ for the same operation time of $18 \mathrm{hrs}$ (Fig. 4).

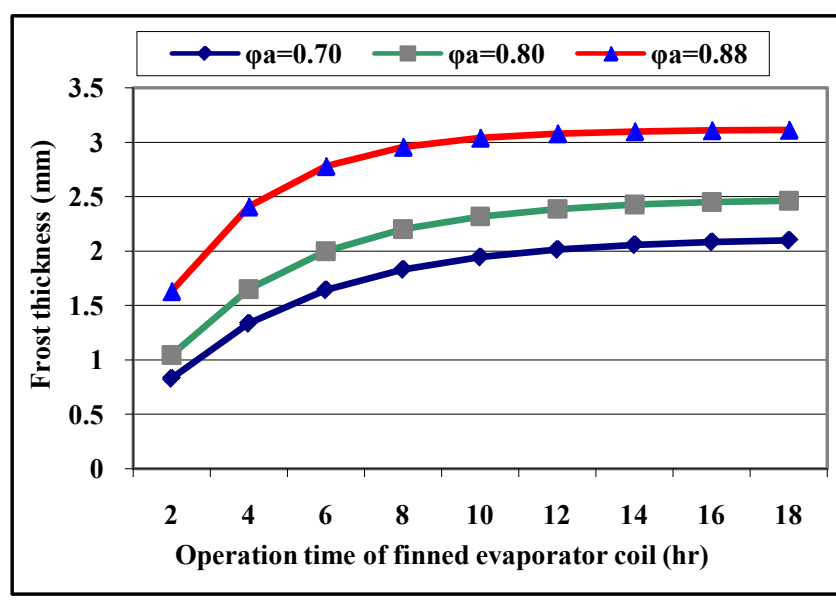

Figure 4. Effect of air relative humidity on the frost thickness at air mass velocity of $4 \mathrm{~kg} / \mathrm{h} \mathrm{m}^{2}$

It means that increasing in relative humidity from 0.70 to 0.88 and mass velocity of air from 2 to 8 at once leads to an increase in frost thickness of $65 \%$ for operation time of 18 hrs (Fig. 5).

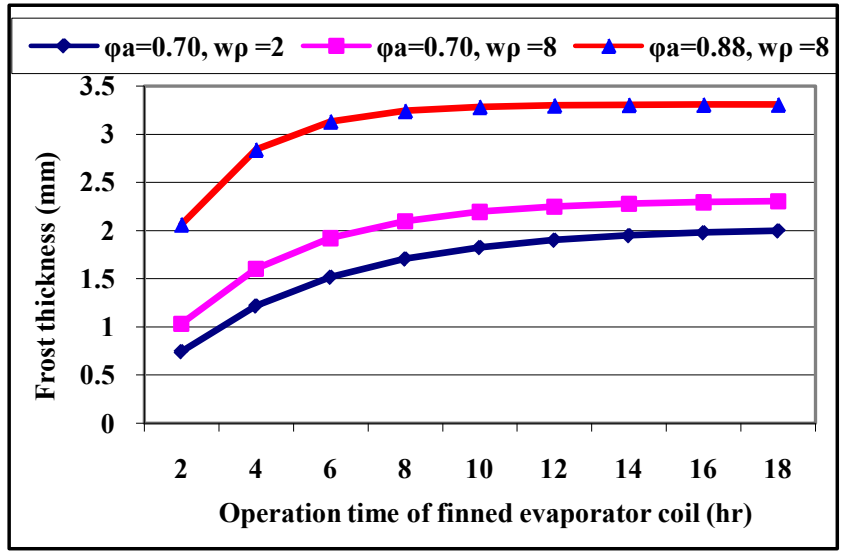

Figure 5. Changing in frost thickness according to changing in relative humidity and mass velocity of air

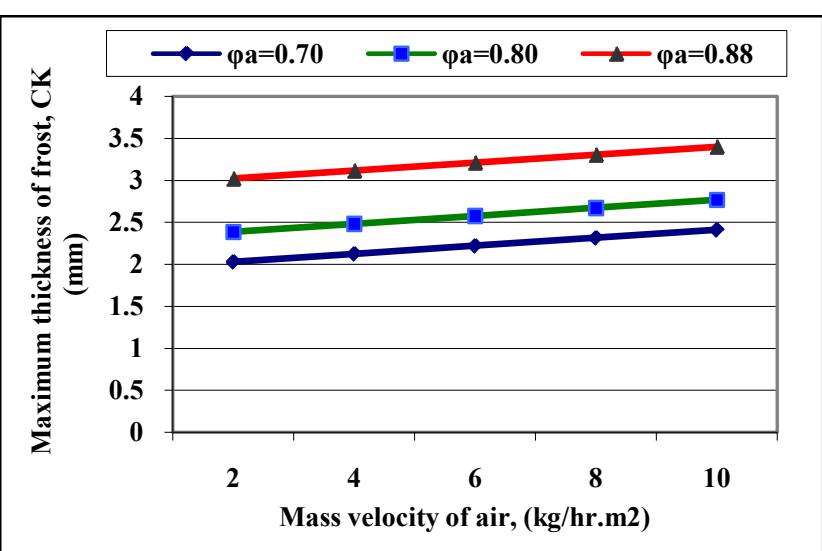

Figure 6. Maximum thickness of frost according to mass velocity and relative humidity of air at unlimited operation time of finned evaporator coil

The intensity of frost accumulation is very appreciable at the first stage of frost formation. The operation time of this stage is variable according to the relative humidity of air. For instance, operation times of this stage are 11,9 and $7 \mathrm{hrs}$ at a relative humidity of $0.70,0.80$ and 0.88 , respectively. After 
this stage, the thickness of frost accumulated on the finned evaporator coil tends to achieve a certain value. The maximum thickness of frost at operation time of $18 \mathrm{hrs}$ (the maximum operation time of refrigeration cycle before defrosting period) is determined (Fig. 6).

The intensity of frost formation will slow down with increases in operation time and decreases in relative humidity and mass velocity of air. The frost mass accumulated on the unit area of finned evaporator surface is calculated according to mass velocity and relative humidity of air. These curves will be useful to design the capacity of defrosting equipment (Fig. 7 and 8).

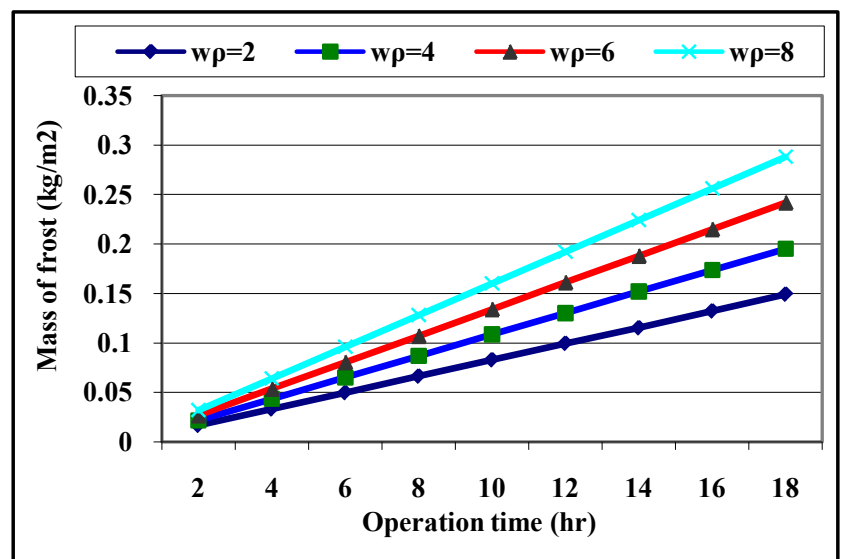

Figure 7. Effect of air mass velocity on the frost mass accumulated on the unit area of the finned evaporator surface at relative humidity of 0.70

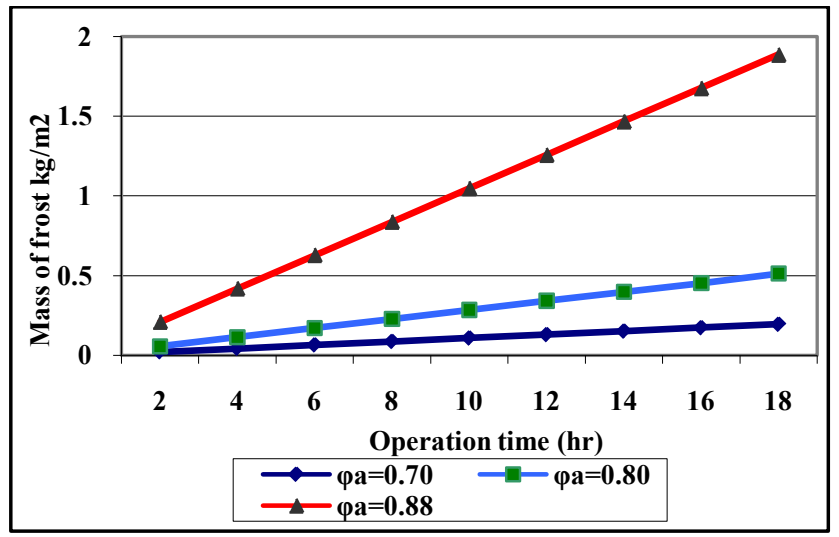

Figure 8. Effect of air relative humidity on the mass of frost accumulated on the unit area of the finned evaporator surface at air mass velocity of 4 $\mathrm{kg} / \mathrm{h} \mathrm{m}^{2}$

\section{Conclusions}

1- The increase in relative humidity from 0.70 to 0.88 and mass velocity of air from 2 to 8 at once leads to a greater frost thickness of $65 \%$ for an operation time of $18 \mathrm{hrs}$.

2- The intensity of frost formation will slow down by increasing operation time and decreasing in the relative humidity and mass velocity of air.

3- The Modified model is flexible and could be used for a more extended study of frost accumulation on finned evaporator coils.

\section{Nomenclatures}

$A_{e}$ :- Area of the finned evaporator coil $\left[\mathrm{m}^{2}\right]$

$C_{k}$ and $C_{T}$ :- Coefficients that consider the effect of mass velocity and relative humidity of the moist air

$\mathrm{C}_{\mathrm{k}}^{1}$ and $\mathrm{C}_{\mathrm{T}}^{1}$ :- Coefficients that consider the effect of moist air relative humidity on the frost thickness

$\mathrm{C}_{\mathrm{g}}$ : - Coefficient considers the effect of relative humidity and mass velocity of air on the intensity of frost mass growth [kg/ hr.m2].

$\mathrm{G}_{\mathrm{f}}$ : - Total frost mass $(\mathrm{kg})$ accumulated on the finned evaporator coil

$\mathrm{g}_{\mathrm{f}}$ : - Frost mass accumulated on unit area of the finned evaporator surface

$\mathrm{V}_{f}$ : - The average speed of the frost accumulation $[\mathrm{mm} /$ $\mathrm{hr}]$

${ }^{\mathrm{w}} \rho$ : - Mass velocity of air $[\mathrm{kg} / \mathrm{hr} . \mathrm{m} 2]$

$\delta_{f}:$ - Thickness of the frost [mm]

$\phi_{a}$ : - Relative humidity of the moist air

$\tau$ : - Operation time $[\mathrm{hr}]$

\section{REFERENCES}

[1] Jeong-Tae Kwon, Hyo Jae Lim, Young-Chul Kwon, Shigeru Koyama, Dong-Hwi Kim and Chieko Kondou, "An experimental study on frosting of laminar air flow on a cold surface with local cooling", International Journal of Refrigeration, Volume 29, Issue 5, August 2006, Pages 754-760.

[2] Y. Hayashi, A. Aoki, S. Adachi and K. Hori, "Study of frost properties correlating with frost formation types", ASME Journal of Heat Transfer 99 (1977), pp. 239-245.

[3] G. Tanda and M. Fossa, "Free convection frost growth in a narrow vertical channel", International Journal of Heat and Mass Transfer, Volume 49, Issues 11-12, June 2006, Pages 1946-1957

[4] Andrew D. Althouse, Carl H. Turnquist, Alfred F. Bracciano "Modern Refrigeration and Air Conditioning", The Goodheart-Willcox Publisher 1988.

[5] Ashrae Handbook 1990, "Refrigeration, Systems and Applications", ISBN 0-910110-70-0.

[6] Ivanova, V. S., 1977, Study finned heat exchangers in air side. Refrigeration Technology, 6: 32-38

[7] Ivanova, V. S., 1978, Building up of frost. Refrigeration Technology, 9: $55-59$. 